\title{
Accent identification by adults with aphasia
}

\author{
Caroline Newton* \\ Developmental Science, Division of Psychology and Language Sciences, \\ University College London
}

Rebecca Burns

Division of Psychology and Language Sciences, University College London

\author{
Carolyn Bruce
}

Language and Communication, Division of Psychology and Language Sciences,

University College London

* Corresponding author

Dr C. Newton, UCL Developmental Science, Chandler House, 2 Wakefield Street, London, United Kingdom, WC1N 1PF

Tel: +44(0)20 76794222

E-mail: caroline.newton@ucl.ac.uk 


\begin{abstract}
The UK is a diverse society where individuals regularly interact with speakers with different accents. Whilst there is a growing body of research on the impact of speaker accent on comprehension in people with aphasia, there is none which explores their ability to identify accents. This study investigated the ability of this group to identify the geographical origins of a speaker. Age-matched participants with and without aphasia listened to 120 audio recordings of five speakers each of six accents, reading aloud four sentences each. Listeners were asked to make a forced-choice decision about the geographical origin of the speaker. Adults with aphasia were significantly less accurate than control participants at identifying accents but both groups made the same pattern of errors. Adults with aphasia who are able to identify a new speaker as being from a particular place may draw on this information to help them "tune in" to the accent.
\end{abstract}

\title{
Keywords
}

Aphasia, adult, accent, categorisation 


\section{Introduction}

Throughout their lives, individuals will encounter a variety of accents which differ from their own in terms of phoneme substitutions, phonetic differences and prosodic patterns. The growth in international immigration over the last half-century in particular means that people are increasingly exposed to language spoken by non-native talkers. In addition, the accents of native speakers, once confined mainly to their region of origin, are now dispersed throughout countries as a result of internal migration. Advances in media have also made mass exposure to different accents possible within the population. These developments have been matched by a rapidly growing body of research focused on the impact of such variation on a listener's comprehension of the spoken message. Findings from research involving adults with no cognitive or communication difficulties indicate that an unfamiliar accent - whether native or non-native - negatively influences language processing especially under adverse listening conditions (e.g. Munro \& Derwing, 1995; Floccia, Goslin, Girard \& Frédérique, 2006; Adank, Evans, Stuart-Smith \& Scott, 2009). Despite this initial processing cost, however, adults have been observed to adapt rapidly to an unfamiliar accent (Clarke \& Garrett, 2004), and to generalise that learning to other speakers with the same accent (Bradlow \& Bent, 2008).

Investigation into the impact of speaker accent on comprehension is also highly important in the clinical arena, as an unfamiliar accent may be particularly challenging for people with communication difficulties, including adults with aphasia, for whom comprehension is already problematic. Research in this area is in its infancy, but has begun to show clear patterns. First, an unfamiliar accent is significantly more difficult to understand for individuals with aphasia than those without aphasia when compared to a familiar accent (Dunton, Bruce \& Newton, 2011). Second, in a study comparing an unfamiliar native accent 
and an unfamiliar non-native accent to a familiar standard accent, Bruce, To and Newton (2012) found that the non-native accent was more problematic than the regional accent. The impact of an unfamiliar native accent, however, becomes more marked when the task requires more processing demands from the listener, such as extracting and recalling information that was implied in an utterance rather than simply stated (Newton \& Bruce, 2011). There is much yet to learn about the comprehension of accents by adults with aphasia, including attempting to unpick the phonological features of specific unfamiliar accents which make them particularly difficult to process, and exploring whether individuals are able to extract the perceptually relevant features of accents. One way of tapping whether they have access to the latter information is to examine accent identification skills. If listeners with aphasia do have access to relevant phonological features of an accent, this might form the basis of clinical work to aid comprehension of accents.

There is some evidence that listeners without aphasia are able to categorise accents with some degree of accuracy in both male and female speakers (Clopper, Conrey and Pisoni, 2005). For example, Williams, Garrett and Coupland (1999) tested the ability of adolescent listeners of six regions of Wales to make a forced-choice categorisation of the accents representative of their regions and Received Pronunciation (RP). Overall accuracy was relatively low at $30 \%$ and participants' accuracy with their own accent only slightly higher at $45 \%$. Clopper and Pisoni (2004) showed similar findings in their study of American undergraduate students listening to six American English accents: they found that their participants' accuracy overall was just above $30 \%$, a rate above chance level. Listeners are more successful when asked to make broader judgements about an accent, so that, for example, when Van Bezooijen \& Gooskens (1999) asked native Dutch and English listeners to identify the Country, Region and Province/Area of accents of Dutch and English respectively, they found marked differences between these levels of categorisation, from 40-52\% for Province/Area to $90-92 \%$ 
for Country. These accuracy scores mirror those found in an early study by Bush (1967) who found that listeners were able to identify the nationality of speakers from the United States, Great Britain and India with 90\% accuracy. These findings may suggest that listeners do not have access to the fine-grained level of detail required to distinguish between some accents. Some of these studies, however, have identified measurable perceptual cues in the speech signal which listeners appear to be using to make their judgments of both native and nonnative accents. These include r-lessness and /æ/ backness as predictors of New England accents (Clopper \& Pisoni, 2004). Vieru, de Mareüil and Adda-Decker (2011) explored French listeners' categorisations of the accents of non-native speakers of French and identified realisation of /b/ as [v] as the distinguishing variant for Spanish and Italian speakers, and that Arabic and German speakers were discriminated by the realization of /d/ as [t], though the authors did not specify word position.

By far the majority of studies of accent identification have involved listeners with a high level of proficiency in the language under examination; adults with aphasia do not have comparable levels of language proficiency. There is a smaller body of research which has explored the ability of non-native listeners to identify accents. Clopper and Bradlow (2009), for example, asked groups of native and non-native listeners to complete a free classification task. The non-native listeners were described as being 'relatively proficient' with written English, with scores on the Test of English as a Foreign Language (TOEFL) ranging from 600 to 673 (maximum $=677$ ). The results of the study showed that the listeners who were learning English were significantly worse at grouping together speakers of the same accent than those who had English as a first language. In contrast to learners of a language, though, people with aphasia are not novice users of a language and bring a considerable level of 
background knowledge to such a task. There is no published research which explores the ability of this group to identify accents. The aims of the study reported here, therefore, are to fill this gap in our knowledge with a set of native accents of English and to determine whether there are any factors (such as age and severity of aphasia) which affect participants' ability to make such decisions. We include participants from the South East of England making forced-choice categorisation of six accents of the British Isles. If adults with aphasia are able to identify a new speaker as being from a particular place, they may be able to draw on this information to help them 'tune in' to that accent, a possibility supported by research which has shown that previous experience with an accent improves perceptual accuracy (Bradlow \& Bent, 2008).

\section{Method}

\section{Participants}

Thirty participants took part in the study, 15 individuals with aphasia and 15 without aphasia. Participants with aphasia attended a community clinic for acquired communication disorders in Central London. They were aged between 29 and 80 years (mean age $=54.3$ years), and there were 11 men and 4 women in the group. All were at least 13 months post-onset with a dominant hemisphere stroke, and had a range of difficulties and levels of aphasia severity, as measured by the Western Aphasia Battery (WAB, Kertesz, 1982). Three of the participants would be considered to have relatively mild aphasia as their Aphasia Quotient on the WAB is above or near the cut-off score of 93.8. These participants were included in this study, because whereas their problems were less evident at the single-word and sentence level, their difficulties were significantly more marked in connected speech contexts. 
Running head: ACCENT IDENTIFICATION BY ADULTS WITH APHASIA

Table 1. Details of participants with aphasia

Western Aphasia Battery

\begin{tabular}{|c|c|c|c|c|c|c|c|c|c|}
\hline \multirow{2}{*}{ P'pant } & \multirow{2}{*}{ Age } & \multirow{2}{*}{ Gender } & \multirow[b]{2}{*}{$\begin{array}{l}\text { English first } \\
\text { language? }\end{array}$} & \multirow[b]{2}{*}{$\begin{array}{l}\text { Months } \\
\text { post-onset }\end{array}$} & \multirow[b]{2}{*}{$\begin{array}{l}\text { Accent } \\
\text { exposure }\end{array}$} & \multirow{2}{*}{ Aud. comp. } & \multirow{2}{*}{ Rep. } & \multirow{2}{*}{ AQ } & \multirow{2}{*}{ Classification } \\
\hline & & & & & & & & & \\
\hline & $\mathrm{M}=54.33$ & & & $M=68.80$ & & $\mathrm{M}=8.68$ & $\mathrm{M}=7.29$ & $M=77.57$ & \\
\hline & $\mathrm{SD}=13.54$ & & & $\mathrm{SD}=74.06$ & & $\mathrm{SD}=1.24$ & $\mathrm{SD}=2.86$ & $\mathrm{SD}=16.16$ & \\
\hline 1 & 80 & $\mathrm{~F}$ & $\mathrm{Y}$ & 242 & 1 & 10 & 10 & 98 & anomic \\
\hline 2 & 72 & M & $\mathrm{Y}$ & 48 & 2 & 8.5 & 8.2 & 81.2 & anomic \\
\hline 3 & 68 & M & $\mathrm{Y}$ & 249 & 1 & 8.5 & 2 & 65.6 & conduction \\
\hline 4 & 62 & M & $\mathrm{Y}$ & 76 & 2 & 7.85 & 8.2 & 73.5 & anomic \\
\hline 5 & 60 & M & $\mathrm{Y}$ & 49 & 0 & 8.9 & 9 & 77.4 & anomic \\
\hline 6 & 59 & M & $\mathrm{Y}$ & 64 & 1 & 9.2 & 9.8 & 95 & anomic \\
\hline 7 & 59 & M & Y & 29 & 2 & 6.3 & 5.7 & 68.2 & Wernicke's \\
\hline
\end{tabular}


Running head: ACCENT IDENTIFICATION BY ADULTS WITH APHASIA

\begin{tabular}{|c|c|c|c|c|c|c|c|c|}
\hline 53 & $\mathrm{~F}$ & $\mathrm{~N}^{1}$ & 31 & 1 & 9.4 & 8 & 82.2 & anomic \\
\hline 53 & M & $\mathrm{Y}$ & 56 & 1 & 9.4 & 3.9 & 54.6 & Broca's \\
\hline 49 & M & $\mathrm{Y}$ & 29 & 2 & 9.5 & 10 & 97.8 & anomic \\
\hline 49 & $\mathrm{~F}$ & $\mathrm{Y}$ & 68 & 1 & 9.2 & 8.4 & 87.8 & anomic \\
\hline 43 & M & $\mathrm{Y}$ & 24 & 0 & 7.6 & 1.4 & 46.6 & Broca's \\
\hline 41 & $\mathrm{~F}$ & $\mathrm{Y}$ & 32 & 2 & 9.85 & 9 & 87.5 & anomic \\
\hline 38 & M & $\mathrm{Y}$ & 22 & 1 & 6.05 & 6 & 57.8 & Broca's \\
\hline 29 & M & $\mathrm{N}^{2}$ & 13 & 2 & 10 & 9.8 & 90.4 & anomic \\
\hline
\end{tabular}

${ }^{1}$ Participant 8's first languages are Ibo, French and Calabar, but she was often required to speak English throughout her early life. She moved to the UK 36 years ago and identified English as the language she predominantly had spoken since then.

${ }^{2}$ The first language of Participant 15 is Polish. He moved to London three years before this study and identified English as the language he predominantly spoke in daily life. 
Thirteen of the participants spoke English as their native language; the remaining two participants reported that English was their dominant language in terms of both frequency and domains of use and had been so since before their stroke. Details of the participants with aphasia are given in table 1.

The control group consisted of 4 men and 11 women, age range 26-82 years; average age, 55.8 years. These were adults with no history of neurological or significant medical conditions, and with English as their native language. An independent samples t-test indicated no significant difference $(t(28)=-.320, p=.752)$ between the ages of the groups. Though the groups were well-matched for age, they were asymmetrical in terms of gender balance. Since no research to-date has reported a gender difference in terms of accent identification and it was important to match the groups in terms of age and life experience (i.e. places they had lived), the partners of the participants with aphasia were included in this study. Individuals were included in the study only if they had passed a hearing screen (Pure Tone Average in the best ear across $1000,2000,4000 \mathrm{~Hz}$ at $25 \mathrm{~dB}$ or below to pass). All of the participants were resident in the London area.

Individuals living in London are likely to have a much higher incidental exposure to a range of accents than those living in other areas of the UK. We asked participants about their experiences of living in regions where they were immersed in accents different to those heard in South East England. Prior to testing, all participants completed a questionnaire, administered by the researcher conducting the experiment, in which they were asked to indicate their exposure to accents by listing the cities or regions in the UK (outside London) in which they had lived for longer than three months. Seven participants with aphasia and five control participants reported exposure to the accents used in this study for at least one 
period of three months through residence, work or family. In order to aid statistical analysis, questionnaire results were categorised numerically:

$0=$ minimal exposure to accents outside of South East England

$1=$ participant exposed to at least one additional accent, but not one featured in this study $2=$ participant exposed to at least one additional accent featured in this study

\section{Stimuli}

The four sentences used in this study were selected from the publicly available corpus of speech data, Intonation Variation in English (IViE; Grabe, Post \& Nolan, 2001) compiled by researchers at the Oxford University Phonetics Laboratory and the Department of Linguistics at the University of Cambridge. This valuable corpus includes recordings of teenage speakers from different parts of the British Isles participating in a variety of reading aloud and speaking tasks in order to look at cross-varietal and stylistic variation in English intonation. The sentences used in this study were edited from recordings of 30 different speakers reading aloud the fairy tale Cinderella, totalling 120 stimuli. These sentences were chosen in preference to the sentence recordings for the IViE project as they were longer, which gave the participants more time to process the perceptual features of the accent. These sentences also contained dialogue in addition to declarative sentences, leading to more variation in prosody. The four sentences contain a range of vowels and consonants, providing a cross-section of perceptual features for each accent:

The girl went and found one, two, three, four mice.

For the third time Cinders' Godmother waved her magic wand. 
"Have we met?" he asked, "and may I have the honour of this dance?"

The prince looked carefully at the girl's face and he recognised her.

Speakers

The speakers were representative of six accents of English spoken in the British Isles:

Belfast, Cardiff, Dublin, Liverpool and Newcastle and Standard Southern British English (sometimes referred to as Received Pronunciation) as spoken in this study by individuals from Cambridge. Five adolescent male speakers were selected for each accent from the IViE Corpus (Grabe et al., 2001). All speakers featured the key prosodic and phonetic characteristics related to their accent (see texts such as Foulkes \& Docherty (1999) and Wells (1982) for fuller details on each).

The Belfast accent is characterised by two realisations of FACE set vowels: here, [e] in "waved" and [eə] in "face" and the production of [a] in BATH set words (with varying lengths amongst our speakers). The latter feature was also apparent in the output of the Cardiff speakers, though this vowel ranged from [a] to [æ:], and the vowel in SQUARE set words (e.g. "carefully”) was realised as a rounded front vowel [ø:]. The Dublin accent is typified by distinctive realisation of LOT and STRUT vowels, so that "godmother" was realised by our speakers with vowels $[a]$ and $[u]$ respectively, alveolar stops in words such as "three" and "third" and lenition of final /t/ and /d/ (so that, for example, "met" was produced as [met]). The accent of the speakers from Liverpool also included lenition of $/ \mathrm{p} /, \mathrm{t} / \mathrm{and} / \mathrm{k} /$, as well as [a] in "dance" and [e:] in "girl". As is characteristic of the accent, all our Newcastle 
speakers produced glottal reinforced variants of /t/ and /k/ (e.g. "went and" ['went?ən]),

FACE vowels were realised as [e] and letterER/commA vowels as [e] so that "godmother" was realised as ['gpdmuðr]. The accent of the speakers from Cambridge was Standard Southern British English.

Using data from the large group of adolescent speakers in the IViE corpus, including those included in this study, Grabe and Post (2002) have outlined the major intonational features of different urban accents in the British Isles. Important features which they highlight include (1) in these accents declarative sentences are predominantly produced with falling intonation, except in Belfast where rising intonation dominates, and (2) for inversion questions a falling pattern dominates in Dublin; elsewhere questions are characterised by rising patterns.

\section{Procedure}

Listeners were tested individually in a sound-proofed room. A Dell Optiplex SX280 desktop computer with 17 " monitor, equipped with a bespoke computer program written in Visual Basic.NET, presented the stimuli and recorded accuracy data. The auditory stimuli were played via the PC's internal speakers. Listeners were asked to identify where each speaker was from, selecting from a forced choice of six cities. The testing screen contained a multiple-choice list of the names of the cities from which listeners made their selection and an outline of the British Isles with the cities marked as a guide (see figure 1).

The stimuli were presented in a computer-generated random order that differed between participants. Stimulus presentation was controlled by the participant, and they could repeat each item once if required. Prior to testing, each participant carried out a practice task which 
included six stimuli, one sentence from each target city produced by different speakers to those included in the main task. Listeners were instructed to associate the standard accent with Cambridge. The participants in both groups carried out the task in one session with a five-minute break. The task and instructions were administered by the second author who has an accent characteristic of the North East of England and had lived in London for three and a half years prior to this study.

Figure 1. Screenshot showing the accent location map and forced choice list of cities

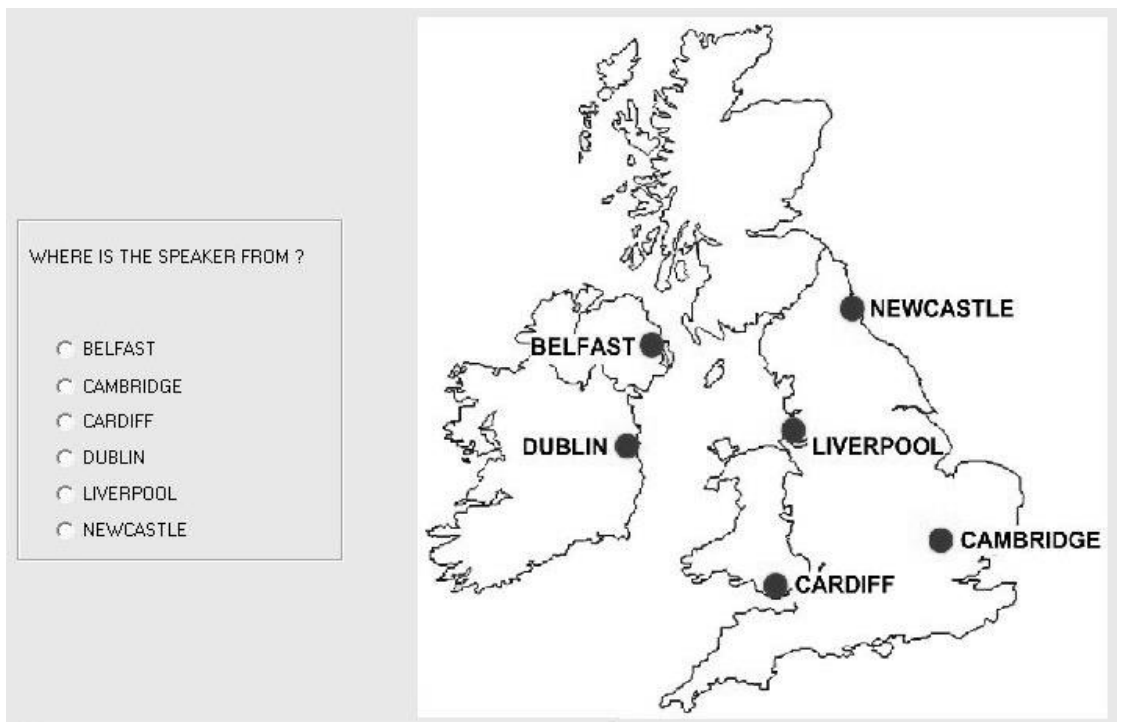

\section{Results}

\section{Accent categorisation}

Correct identification scores are shown in figure 2, separately for each accent for the two groups of participants. The average correct identification score (out of 20) was 10.81 for the participants with aphasia (range: 8.33-17.33) and 14 for those without aphasia (range: 10.80 19.13). All these scores are significantly above chance $\left(\chi^{2}, p<.01\right)$. The two participants with aphasia whose first language was not English scored in the mid-range of the group with aphasia in all the accent conditions. 
Homogeneity assumptions were met on a box test of equality of covariance matrices. Some variables were not normally distributed. However, a two-way mixed design ANOVA was carried out, which is robust against normality deviations, with accent (six levels: Belfast, Cambridge, Cardiff, Dublin, Liverpool and Newcastle) as the within-subjects factor and group (two levels: aphasic and control) as the between-subjects factor. Mauchly's test indicated that the assumption of sphericity was violated $\left(\chi^{2}(14)=38.95, p<.001\right)$, so the Greenhouse-Geisser correction was used where appropriate. The ANOVA revealed that the performance of the individuals with aphasia was significantly worse than the individuals without aphasia $\left(\mathrm{F}(1,28)=5.065, p=.032, \eta_{\mathrm{p}}{ }^{2}=.153\right)$, and that some accents were more accurately categorised than others $\left(\mathrm{F}(3.496,97.902)=41.297, p<0.001, \eta_{\mathrm{p}}{ }^{2}=.596\right)-$ see figure 2. However, there was no significant interaction between accent and group $(\mathrm{F}(3.496$, $\left.97.902)=1.493, p=.129, \eta_{\mathrm{p}}{ }^{2}=.051\right)$, indicating that there was no difference between the groups in terms of how they responded to the different accents.

Figure 2. Scores group-by-accent interaction (error bars show 95\% confidence intervals)

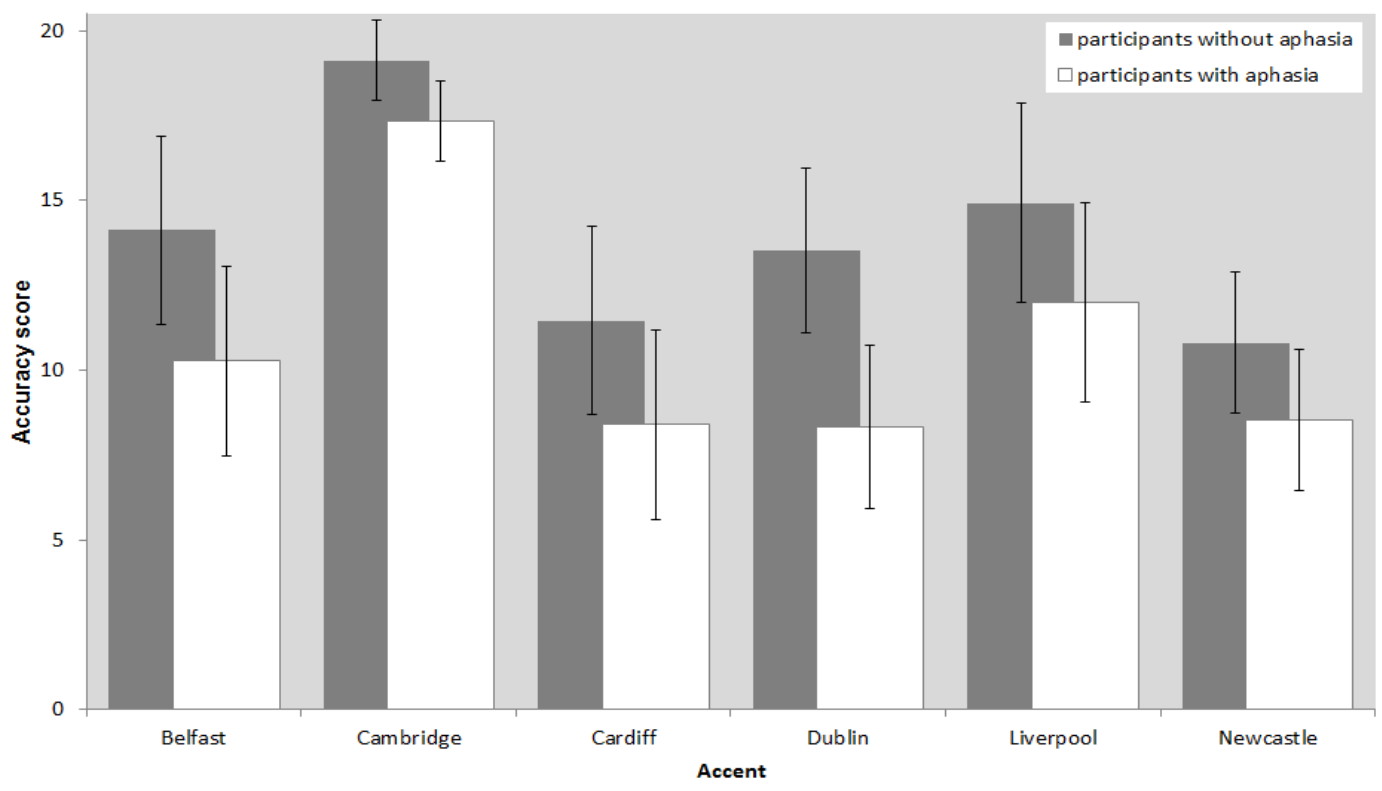


Follow-up analysis using pairwise comparisons revealed that participants in both groups were significantly more accurate in categorising the Cambridge (standard) accent than all the other accents. Accuracy scores for Cardiff, Dublin and Newcastle were all significantly worse than those for both Belfast and Liverpool in the participants with aphasia. For those without aphasia, accuracy scores for Cardiff and Newcastle were significantly worse than Belfast, Dublin and Liverpool (see figure 2).

\section{Error patterns}

Figure 3: Dendrogram generated by the hierarchical cluster analysis results for participants with and without aphasia

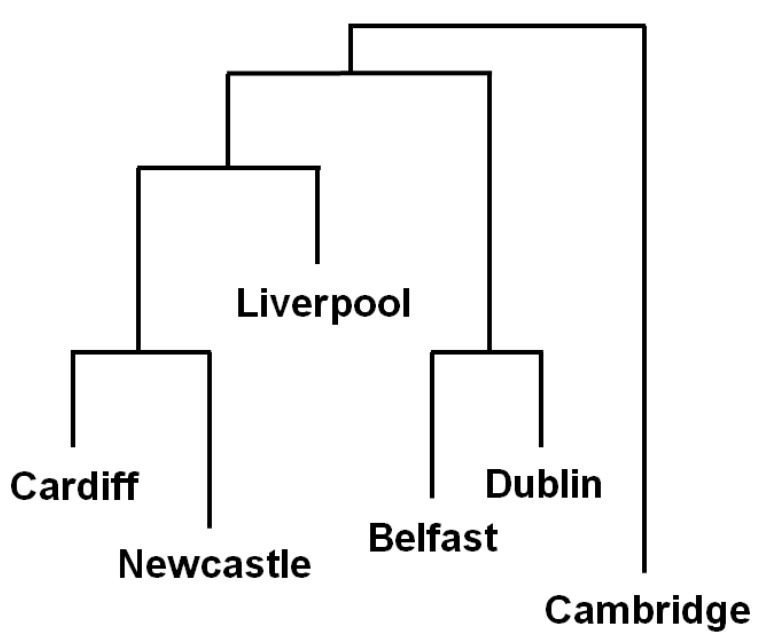

Stimulus-response confusion matrices were calculated from the responses obtained for each listener group. Inspection of these suggested that listeners' errors were not random but revealed consistent patterns of perceptual confusions, and that there was a high degree of reciprocity between some of the cities. These matrices were submitted to two separate hierarchical cluster analyses using Ward's method. This kind of analysis (used commonly in accent categorisation studies; e.g. Clopper \& Pisoni, 2004; Vieru et al., 2011) generates a 
dendrogram which gives an estimation of the number of likely clusters within the error patterns. In this case they indicated that although participants with aphasia made a greater number of errors than the control group, the pattern of errors for the two groups was identical: the Belfast and Dublin accents were commonly confused, as were Cardiff, Newcastle and Liverpool (see figure 3).

\section{Effect of accent exposure}

In order to explore the effect of exposure to accent on identification accuracy, a three-way between subjects ANOVA was carried out with environmental exposure to accents as the within-subjects factor (three levels: no exposure, general exposure to accents and taskspecific accent exposure) and group (two levels: aphasic and control) as the between subjects factor. As above, there was a significant main effect of group $\left(\mathrm{F}(1,24)=4.700, p=.04, \eta_{\mathrm{p}}{ }^{2}=\right.$ .164). However, no significant difference was found for environmental exposure $(F(2,24)=$ $\left.2.181, p=.135, \eta_{\mathrm{p}}{ }^{2}=.154\right)$, and the interaction between group and exposure was not significant $\left(\mathrm{F}(2,24)=.175, p=.841, \eta_{\mathrm{p}}^{2}=.014\right)$. Exposure to one or more accents for a period greater than three months did not affect accent categorisation for adults with or without aphasia.

\section{Effect of age, severity of aphasia and other factors}

Overall mean categorisation scores were analysed in relation to age. Normality and variance assumptions were met, so Pearson's correlation tests were carried out. These analyses revealed that there was no linear correlation between age and overall mean score for the control participants $(r=-.377, p=.167)$. Similarly, there was not a significant correlation between age and overall mean score for adults with aphasia $(r=-.286, p=.302)$, indicating 
that age does not appear to be related to the ability to categorise accents for adults with or without aphasia.

The overall mean categorisation scores for the participants with aphasia were analysed in relation to the WAB aphasia quotient and two of the individual subtests which it was considered might have a relationship with performance on this task: auditory comprehension and repetition. Data for the latter task did not meet the assumptions for the Pearson's correlation as they were not normally-distributed, and so a Spearman's correlation was calculated with respect to those data. There were no statistically significant correlations between overall mean score and any of the scores from the WAB. Neither was there any correlation between the number of months since stroke and participants' performance on the identification task.

\section{Discussion}

Performance on the six forced-choice categorisation task by both sets of participants was significantly above chance for all accents, and with the average accuracy percentages being $54 \%$ for those with aphasia and $70 \%$ for the control participants, these scores are higher than those for the narrower categories of identification reported in previous literature (e.g. 52\% for Area of England reported by Van Bezooijen \& Gooskens, 1999). This difference is striking, not least because there is considerable overlap between the accents used by Van Bezooijen and Gooskens and those included here: both include speakers from Newcastle, Belfast and South Wales. Differences may be due to the fact that in their study a single stimulus was included for each of three speakers of each accent; in our study there were four stimuli for each of five talkers and therefore our participants may simply have had more to information to help them to 'tune in' to each accent. 
A listener's age did not appear to be related to his or her ability to categorise the accents, whether he or she had aphasia or not. It might be expected that older participants would have benefitted from their greater experience with different accents and therefore perform better in the task than the younger listeners. Conversely, it could be argued that the cognitive and sensory changes associated with aging (e.g. Wingfield, Tun \& McCoy, 2005) might result in poorer performance by the older listeners. In this case, where no effect of age was observed, it may be that each of these factors counteracts the other, or that the relatively small sample size prevents either effect from being observed.

Adults with aphasia achieved significantly lower overall mean scores than the participants without aphasia, and some of those individuals reported anecdotally that they would have had less difficulty with the task prior to their stroke. This indicates that the impairments associated with aphasia interfere with the processes of accent categorisation in some way. The poorer performance may have arisen due to a number of reasons. First, the participants with aphasia may have greater difficulty processing the accent without also attempting to comprehend the language and the stimuli were relatively complex syntactically. Consequently, interference from language processing may result in diminished resources available to access the perceptual cues of accents. Clopper and Bradlow (2009) found nonnative listeners of English less accurate in categorising four American English accents. Though the groups are arguably comparable in terms of lower proficiency in English they are not at all comparable in terms of exposure to the language and background knowledge about the culture - in both of which adults with aphasia have a significant advantage. This difference is borne out when considering the patterns of errors highlighted in the cluster analysis. Note too that we did not find any relationship between level of language functioning and performance on our task (though this may have been due to the relatively small sample size). A second possible explanation for the difference in categorisation ability is that the 
adults with aphasia may have diminished working memory capacity (Martin, Kohena, Kalinyak-Fliszara, Soverib, \& Laineb, 2012), which would interfere with their ability to store the sentences whilst extracting perceptual cues and applying existing knowledge of accents before making a decision in the task. Research suggests that adults with aphasia require longer to process speech in an unfamiliar accent (Dunton et al., 2011) which may be due to greater demands on working memory. Finally, while several of the participants without aphasia either demonstrated or reported strategies to help them make the judgements required in completing the task, none of these were found among the participants with aphasia. Strategies included:

- Repeating the sentence whilst mimicking the accent.

- Mimicking or exaggerating a distinctive feature of the accent presented which was not present in the other accents. For example, /a:/ in the Cambridge version of "dance"; /t/ in the Dublin version of "three".

- Naming a well-known figure who shared that accent. For example, one participant said "Steven Gerrard" (a well-known professional footballer from Liverpool) following stimuli from Liverpool.

- Employing a task-related strategy. For example, excluding all other possibilities before making a selection rather than making the selection based on a positive identification.

Individuals with aphasia may, of course, have been employing such strategies but may have been unable to articulate them because of expressive language difficulties. Alternatively, this group of participants may have been less able to adopt strategies because of an impairment to executive functioning. Strategy use is highly dependent on executive functioning skills, and 
though we did not collect the relevant data from our participants, decreased executive functioning skills have been found in people with aphasia (e.g. Purdy, 2002; Purdy \& Dietz, 2010; Allen, Martin \& Martin, 2012).

Although the participants with aphasia performed more poorly than those without, note that we found no interaction between group and accent type so that both groups behaved similarly with respect to the individual accents: accents that were difficult to categorise for the control participants were also difficult for participants with aphasia. As with previous research, there were marked differences between the accents in terms of their identifiableness. It might be argued that asking listeners to associate the standard accent with the small town of Cambridge would present them with a cognitively more demanding task than required for the other accents and that, consequently, the Cambridge accent would produce lower identification scores. However, this is not borne out in our findings. The standard accent (Cambridge) was most accurately identified, with those from Cardiff and Newcastle proving the most difficult to categorise. Some researchers have suggested that differences between accents in identification accuracy may be a result of different levels of exposure to those accents (Stephan, 1997; Bayard, Weatherall, Gallois \& Pittam, 2001). We collected information from our participants on their exposure to the accents used in this study and found no relationship between exposure and accuracy - though it is possible that our measure of exposure was not sensitive enough to pick up effects relating to any one specific accent. An alternative explanation for the accuracy score differences is that speakers of those accents lacked some of the unique phonetic features which the listeners had stored for talkers from those cities or that the information listeners had stored about these accents was less detailed. There is some research evidence which suggests that when listeners hear an accent which is different from their own, they make use of the phonetic information they have stored for that particular accent category to assist in speech perception, and can draw on the category label 
associated with this information to state where the speaker is from (Niedzielski, 1999; Hay, Nolan \& Drager, 2006).

The confusion matrices and clustering analyses carried out show that there are clear patterns in the errors made by the participants. The accents of Belfast and Dublin were commonly confused. Phonetically, the reasons for this are unclear: though both rhotic, the accents are quite distinct with the vowel system of the Belfast accent more closely resembling that of Scottish accents than Dublin. Prosodically, the Belfast accent has an intonation pattern which is distinctively different from the Dublin accent. It may be that listeners assigned some stimuli which lacked the distinctive features of a specific accent to the category 'Irish', or that an 'Irish' category was one for which they had specified phonetic information (Hay et al., 2006; Niedzielski, 1999). The confusions between Cardiff, Newcastle and (to a lesser extent) Liverpool are even more difficult to unpick, though the clustering of these accents may simply be a consequence of similar prosody, the high accuracy scores for the Cambridge accent and their lack of 'Irishness'. This mirrors some findings of Kerswill and Williams (2002), who in their study of dialect identification among adolescent listeners, suggest that less distinctive accents are likely to be less easily recognized. We did not, in this study, measure the acoustic-phonetic cues that the listeners might have been relying on in making their categorisation judgements; without the valuable insight that these would have provided, it is difficult to determine what underpinned the patterns of errors made.

These analyses indicate that, although people with aphasia performed less accurately than those without aphasia, they showed a similar pattern of errors. Specifically - and importantly - their errors were not random: where accents were incorrectly categorised, the errors showed the same confusions as the control group. Unlike the non-native listeners of Clopper and Bradlow's (2009) study, our participants with aphasia show that they are able to pick up on 
the perceptually relevant features in accents and draw on background knowledge to use these features in the task of identification. The link between comprehension and identification should be explored further, as a limitation of our study is that we did not collect information on our listeners' comprehension of the accents under examination. With this caveat in mind, we believe our findings provide the basis for further work in this area. Although differences in phonological information in accents may have a negative impact on language comprehension, our study suggests that those with aphasia are still able to make use of phonological information in the speech signal to make their judgements. Individuals who are able to do this may be able to draw on this information to help them 'tune in' to the accent and thus to improve comprehension. Recognising where a speaker is from should enable access to phonetically rich information that a listener has stored about the accent associated with that location; the listener can then use the relationship between that information and their own representations to guide their subsequent processing of incoming speech (Nygaard \& Pisoni, 1998).

\section{Acknowledgements}

The authors wish to thank the participants who contributed to the study.

\section{Declaration of interest}

The authors report no conflicts of interest. The authors alone are responsible for the content and writing of the paper. 


\section{References}

Adank, P., Evans, B., Stuart-Smith, J. \& Scott, S.K. (2009). Comprehension of familiar and unfamiliar native accents under adverse listening conditions. Journal of Experimental Psychology: Human Perception and Performance, 35, 520-529.

Allen, C.M., Randi, C., Martin, R.C. \& Martin, N. (2012). Relations between short-term memory deficits, semantic processing, and executive function. Aphasiology, 26, 428-461.

Bayard, D., Weatherall, A., Gallois, C. \& Pittam, J. (2001). Pax Americana? Accent attitudinal evaluations in New Zealand, Australia and America. Journal of Sociolinguistics, 5, 22-49.

Bradlow, A.R. \& Bent, T. (2008). Perceptual adaptation to non-native speech. Cognition, $106,707-729$

Bruce, C., To, C.T. \& Newton, C. (2012). Accent on communication: The impact of regional and foreign accent on comprehension in adults with aphasia. Disability \& Rehabilitation, $34,1024-1029$.

Bush, C. N. (1967). Some acoustic parameters of speech and their relationships to the perception of dialect differences. TESOL Quarterly, 1, 20-30.

Clarke, C.M. \& Garrett, M.F. (2004). Rapid adaptation to foreign-accented English. Journal of the Acoustical Society of America, 116, 3647-3658.

Clopper, C.G. \& Bradlow, A.R. (2009). Free classification of American English dialects by native and non-native listeners. Journal of Phonetics, 37, 436-451.

Clopper, C. \& Pisoni, D. (2004). Some acoustic cues for the perceptual categorization of American English regional dialects. Journal of Phonetics, 32,111-140. 
Clopper, C.G., Conrey, B. \& Pisoni, D.B. (2005). Effects of talker gender on dialect categorization. Journal of Language and Social Psychology, 24, 182-206.

Dunton, J., Bruce, C. \& Newton, C. (2011). Investigating the impact of unfamiliar speaker accent on auditory comprehension in adults with aphasia. International Journal of Language \& Communication Disorders, 46, 63-73

Floccia, C., Goslin, J., Girard, F. \& Konopczynski, G. (2006). Does a regional accent perturb speech processing? Journal of Experimental Psychology: Human Perception and Performance, 32, 1276-1293.

Foulkes, P. \& Docherty, G.J. (Eds.) (1999). Urban voices: accent studies in the British Isles. London: Arnold.

Grabe, E. \& Post, B. (2002). Intonational Variation in English. In B.Bel and I. Marlin (Eds.), Proceedings of the Speech Prosody 2002 Conference, 11-13 April 2002, Aix-enProvence: Laboratoire Parole et Langage, 343-346.

Grabe, E., Post, B. and Nolan, F. (2001).The IViE Corpus [data file]. Retrieved from http://www.phon.ox.ac.uk/files/apps/old_IViE/

Hay, J., Nolan, A. \& Drager, K. (2006). From fush to feesh: Exemplar priming in speech perception. The Linguistic Review, 23, 351-379.

Kerswill, P., \& Williams, A. (2002). Dialect recognition and speech community focusing in new and old towns in England: The effects of dialect leveling, demography and social networks. In D. Long (Ed.), Handbook of perceptual dialectology (Vol. 2, pp. 173-205). Philadelphia, PA: John Benjamins. 
Kertesz, A. (1982). Western Aphasia Battery (WAB). San Antonio, TX: Psychological Corporation.

Martin, N., Kohena, K., Kalinyak-Fliszara, M., Soverib, A. \& Laineb, M. (2012). Effects of working memory load on processing of sounds and meanings of words in aphasia. Aphasiology, 26, 462-493.

Munro, M.J. \& Derwing, T.M. (1995). Processing time, accent, and comprehensibility in the perception of native and foreign-accented speech. Language and Speech, 38, 289-306.

Newton, C. \& Bruce, C. (2011). Accent on aphasia. Speech \& Language Therapy in Practice, Summer, 11 .

Niedzielski, N. (1999). The effect of social information on the perception of sociolinguistic variables. Journal of Language and Social Psychology, 18, 62-85.

Nygaard, L. C., \& Pisoni, D. B. (1998). Talker-specific learning in speech perception. Perception and Psychophysics, 60, 355-376.

Purdy, M. H. (2002). Executive function ability in persons with aphasia. Aphasiology, 16, $549-557$

Purdy, M. \& Dietz, A. (2010). Factors influencing AAC usage by individuals with aphasia. Perspectives on Augmentative and Alternative Communication, 19, 70-78

Stephan, C. (1997).The unknown Englishes? Testing German students' ability to identify varieties of English. In E.W. Schneider (Ed.), Englishes around the world (pp. 93-108). Amsterdam: John Benjamins. 
Van Bezooijen, R., \& Gooskens, C. (1999). Identification of language varieties: The contribution of different linguistic levels. Journal of Language and Social Psychology, 18, $31-48$.

Vieru, B., de Mareüil, P. B. \& Adda-Decker, M. (2011). Characterisation and identification of non-native French accents. Speech Communication, 53, 292-310.

Wells, J. C. (1982). Accents of English 2: The British Isles. Cambridge: Cambridge University Press.

Williams, A., Garrett, P., \& Coupland, N. (1999). Dialect recognition. In D. R. Preston (Ed.), Handbook of perceptual dialectology (pp. 345-358). Philadelphia: John Benjamins.

Wingfield, A., Tun, P.A. \& McCoy, S.L. (2005). Hearing loss in older adulthood: What it is and how it interacts with cognitive performance. Current Directions in Psychological Science, 14, 144-148. 